\title{
O DILEMA DE SELLARS: DESAFIO AO FUNDACIONISMO EPISTÊMICO
}

Carlos Augusto Sartori *

RESUMO - O fundacionismo epistêmico enfrenta uma grave objeção em relação às crenças básicas que se colocam como fundamento da justificação e do conhecimento: o conhecido problema de Sellars. Aqui, tenta-se caracterizar o problema proposto por Sellars e apresentar algumas respostas que parecem bastante plausíveis, a partir de um entendimento da experiência sensorial e da própria natureza da percepção, que permite contornar o problema e defender uma versão de fundacionismo moderado.

PALAVRAS-CHAVE - Fundacionismo epistêmico. Dilema de Sellars. O dado. Percepção.

\begin{abstract}
Epistemic foundationalism is confronted with a serious objection in relation to the basic beliefs placed as the foundation of justification and knowledge: the well-known Sellars's problem. We try to characterize the problem advanced by Sellars and show some plausible answers which depend on the understanding of sensory experience and the very nature of perception, which allows us to avoid the objection and defend a moderate version of foundationalism.

KEYWORDS - Epistemic foundationalism. Sellars' dilemma. The given. Perception.
\end{abstract}

\section{O fundacionismo clássico e as crenças básicas}

Em relação à justificação das nossas crenças sobre o mundo exterior, o fundacionismo epistêmico, em suas várias formas, assume que há certas crenças cuja justificação não depende de outras crenças: são as crenças básicas, que constituem os fundamentos, a base de toda a justificação epistêmica. Além disso, qualquer forma de fundacionismo assume que a justificação de todas as crenças não-básicas é derivada inferencialmente de crenças básicas. Assim, apoiado no argumento do regresso epistêmico, o fundacionismo afirma que, se há crenças justificadas, então há crenças diretamente justificadas e, para explicar o que pode servir como crença

* Professor do Departamento de Filosofia da Universidade Federal de Santa Maria. carlos.sartori@terra.com.br.

\begin{tabular}{|l|l|l|l|l|l|}
\hline VERITAS & Porto Alegre & v. 54 & n. 2 & maio/ago. 2009 & p. 96-108 \\
\hline
\end{tabular}


básica, os fundacionistas defendem a ideia de que elas são derivadas da experiência e são por ela justificadas.

Ora, a história da filosofia consagrou a análise do conhecimento como crença verdadeira justificada, até que Gettier (1963) apresentou seus contraexemplos, e passou-se a exigir alguma coisa a mais. Mas, mesmo assim, pode-se manter que o conhecimento envolve pelo menos uma crença verdadeira justificada. E, justamente por ser esse o entendimento ortodoxo sobre a análise adequada do conhecimento, levantam-se sérios problemas, em particular, o problema de Sellars: "Se o conhecimento é uma crença verdadeira justificada, como pode existir uma coisa tal como conhecimento autoevidente? $\mathrm{E}$, se não há uma coisa tal como conhecimento autoevidente, como pode qualquer crença verdadeira, no sentido relevante, ser justificada?" (Sellars, 2000a, p. 125). O sentido relevante a que Sellars se refere é a questão de se temos ou não boas razões para pensar que nossas crenças são verdadeiras, isto é, se nossas crenças descrevem o mundo exterior mais ou menos como ele é. Mas, que boas razões devem ser essas? Como mostra Sellars, "somos tentados a distinguir uma classe de casos em que as razões são não apenas boas o suficiente para justificar crer que $p$, mas também boas o suficiente para tornar absurdo não crer que p" (id. ib., p. 126). Assim, para um sujeito epistêmico $S$ que tem a crença de que há um gato branco no telhado, pode-se solicitar que ele diga o que faz com que ele pense que essa crença seja verdadeira. A resposta que $S$ apresenta é que ele está vendo um gato branco no telhado, e essa é a boa razão que $S$ tem para crer que tem um gato branco no telhado. Mas, se a justificação tem a ver com as boas razões, então é difícil, dirá Sellars, entender como a justificação de uma crença não é inferencial, "pois o conceito de uma razão parece tão claramente atrelada ao de uma inferência ou argumento que o conceito de razoabilidade não-inferencial parece ser uma contradictio in adjecto" (ib. p. 127). Por outro lado, é muito antiga a idéia de que nem toda justificação é inferencial. Aristóteles, por exemplo, diz que, se toda justificação fosse inferencial, então ela seria impossível, uma vez que isso imporia ou um regresso infinito, em que não se poderia supor nenhuma premissa que desse início a uma inferência válida, ou um raciocínio circular, em que a demonstração se daria em círculo e pela reciprocidade entre as proposições, o que não é admissível (cf. Analytica posteriora 72b3). Também não é razoável que o regresso seja interrompido arbitrariamente, supondo-se que haja alguma crença que dá origem a uma justificação sem que ela mesma seja ou precise ser justificada. Portanto, se há justificação, então é preciso admitir que para algumas crenças a justificação não é inferencial. O que caracteriza o fundacionismo epistêmico, então, é a admissão de que (1) existem crenças básicas (crenças fundacionais), 
(2) existem crenças não-básicas (crenças da superestrutura) e (3) a justificação das crenças não-básicas se deve, em última análise, às crenças básicas.

De maneira geral, o fundacionismo admite que a fonte de justificação das crenças básicas é a experiência sensorial, e, vale lembrar, trata-se aqui de crenças empíricas. Surge então a pergunta que os fundacionistas são convidados a responder: Como a experiência sensorial pode desempenhar o papel de justificador de crenças? Os fundacionistas terão que explicar qual é a relação que há entre a experiência sensorial e a crença para que esta seja adequadamente justificada por aquela.

Em uma visão clássica ou tradicional, o fundacionismo argumenta que as crenças básicas não podem ser crenças derivadas da percepção ordinária, já que um sujeito $S$ poderia estar enganado, dada a falibilidade das percepções: é razoável pensar, por exemplo, que, se $S$ entrasse numa sala e observasse um certo objeto verde sobre uma mesa, ele diria que há um objeto verde sobre a mesa. Todavia, talvez por razões artísticas, trata-se de um objeto branco convenientemente iluminado por luzes verdes para dar um certo efeito e, por isso, ocorre o engano de $S: S$ percebe algo verde quando, na verdade, não é verde. O fundacionista clássico dirá que as crenças básicas devem ser perceptuais apenas no sentido de como as coisas se apresentam ao observador: "crenças básicas devem ser perceptuais em certo sentido, mas elas não precisam ser crenças sobre objetos físicos. Eu posso estar errado a respeito da cor que uma coisa tem, mas não é tão óbvio que eu possa estar errado sobre a cor que aparece a mim" (Pollock \& Cruz, 1999, p. 31). São, portanto, as experiências sensoriais que fazem o sujeito de conhecimento formar crenças sobre seu ambiente físico. Assim, $S$ pode se enganar quando ele vê um gato branco no telhado, mas não pode se enganar quanto a estar tendo a experiência visual de algo que lhe aparece como sendo um gato branco no telhado. Ele estaria experienciando algo como se fosse um gato branco no telhado, ou então algo está aparecendo a ele algo como se fosse um gato branco no telhado, e esse é o caráter das experiências sensoriais. O que motiva a aceitar essas crenças de aparência, as crenças baseadas naquilo que aparece a alguém como se fosse $x$, é a pressuposição de que uma crença que pode ser falsa não pode ser básica e também que as crenças de aparência não podem estar erradas. Assim, os fundacionistas tradicionais, representados, apenas para citar alguns, por Descartes, Locke, Ayer e Russell e, mais recentemente, por BonJour, Fumerton e McGrew, defendem que as crenças básicas são crenças sobre objetos mentais que se apresentam diretamente à consciência, ou, em outras palavras, são crenças sobre os próprios estados mentais do agente doxástico ou sujeito de conhecimento, estados esses que seriam relatados 
através de uma estrutura linguística do tipo 'eu estou experienciando isto', em que 'isto' representa a própria experiência que se está tendo. Segundo os fundacionistas tradicionais, dado um certo estado mental $x$, se $S$ está em $x$ e pensa estar no estado mental $x$, então ele formula a crença verdadeira de que ele está no estado mental $x$. Esses estados mentais são autoevidentes ou autoapresentantes e constituem o que se conhece como "o dado" (the given).

Juntamente com a teoria do dado, portanto, está a tese da infalibilidade das crenças básicas. Uma vez que as crenças básicas são crenças a respeito dos próprios estados mentais do sujeito, ao formulá-las o sujeito não pode estar errado e, portanto, está plenamente justificado. Repetindo BonJour, "a tese central da doutrina do dado é que crenças empíricas básicas são justificadas, não por apelo a outras crenças ou fatos externos, mas por apelo à 'experiência imediata' ou 'apreensão direta' ou a 'intuições' - estados que supostamente podem conferir justificação sem que eles mesmos precisem de justificação" (1985, p. 59). Assim, quando $S$ vê um gato branco no telhado, ele não consegue deixar de crer que ele está tendo a experiência de estar vendo um gato branco no telhado. Essa crença é tão irresistível que se confere a ela um estatuto epistêmico especial, e ela é justificada porque o que $S$ imediatamente experiencia ou apreende é o próprio fato, ou propriedade, ou estado de coisas, que torna verdadeira a crença dele de que há um gato branco no telhado.

\section{O dilema de Sellars e a resposta do fundacionismo moderado}

Wilfrid Sellars (2000b) apresenta uma caracterização dos dados supostos pelos fundacionistas como base de todo conhecimento empírico que vai culminar na formulação de uma grave objeção ao fundacionismo epistêmico. Conforme a descrição que ele apresenta, o fundacionista supõe que a base estrutural do conhecimento contenha fatos que são conhecidos não inferencialmente e, ao mesmo tempo, não requer qualquer outro conhecimento de fatos particulares ou verdades gerais. Além disso, essa estrutura de conhecimentos não inferenciais constitui a instância para a qual retrocede a cadeia epistêmica e onde esta é interrompida. Assim, qualquer enunciado que expresse um fato que pertence a essa estrutura de base deverá ter uma autoridade ou credibilidade que não depende de nenhum outro enunciado, devendo, portanto, ser formulado de uma maneira que envolve essa credibilidade. Esses enunciados são relatos observacionais que "assemelham-se a enunciados analíticos porque serem feitos corretamente é uma condição suficiente e necessária de sua verdade" (p. 261). Ser feito corretamente consiste em seguir regras de uso das palavras contidas no enunciado: relatar corretamente 'Tem um gato branco no telhado' consiste em seguir as regras de uso das palavras 
'tem', 'um', 'gato', 'branco', 'no' e 'telhado', e esse relato tem autoridade porque se apoia em uma consciência não verbal de que algo é o caso, a consciência de que tem um gato branco no telhado. Essa interpretação de "relatar corretamente" trata um relato observacional como se fosse uma ação e, como tal, sua correção é análoga à correção de uma ação. Todavia, um relato observacional não precisa ser entendido como análogo a uma ação e sua autoridade pode advir da inferência que se faz de que se está na presença de uma porção de realidade porque alguém fez um relato assim e assim. Nesse sentido, "um relato pode ser correto por ser uma instância de um modo geral de comportamento que, em uma dada comunidade linguística, é razoável sancionar e apoiar" (p. 263).

A autoridade de um relato observacional não é suficiente para que seu enunciado expresse conhecimento, pois "essa autoridade tem que ser em algum sentido reconhecida pela pessoa de que é o relato" (p. 263). Para Sellars, esse é um problema difícil de superar, porque a autoridade de um relato observacional advém da inferência de que há algo assim e assim a partir do relato de que há algo assim e assim. Portanto, somente a pessoa que é capaz de fazer essa inferência poderia reconhecer a autoridade do relato observacional, já que, se fosse o relato 'Tem um gato branco no telhado', a pessoa teria que ter o conceito de 'gato', 'branco' e 'telhado' e também o conceito de condições normais de percepção. Assim, o enunciado 'Tem um gato branco no telhado' expressará conhecimento somente se indica a presença de um gato branco no telhado e aquele que enuncia ou faz esse relato sabe reconhecer as instâncias desse relato que são indicadoras de que há um gato branco no telhado, se as condições normais de percepção forem normais. Dessa forma, para se ter conhecimento de que tem um gato branco no telhado, pressupõe-se o conhecimento geral de que 'Tem um gato branco no telhado' indica confiavelmente que se está na presença de um gato branco no telhado, ou seja, para $S$ saber que tem um gato branco no telhado é preciso que ele saiba também fatos gerais da forma ' $X$ é um sintoma, sinal ou indicação confiável de $Y^{\prime}$, e, portanto, não é possível que os enunciados que se referem aos fatos da estrutura básica sejam logicamente independentes de outros enunciados. Isso constitui o golpe de Sellars contra o fundacionismo tradicional, com a conclusão de que não se pode fazer atribuições de conhecimento empírico sem que se atribua também ao sujeito certos conhecimentos de verdades gerais.

No seu estudo sobre o problema de Sellars, BonJour (1985), na sua fase coerentista, mostra que o que há de atrativo nas teorias fundacionistas tradicionais é que o apelo justificatório das crenças ao que é dado ou imediatamente apreendido é um apelo direto ao mundo objetivo, e isso dispensa o recurso justificatório a outras crenças, interrompendo o 
regresso epistêmico. Além disso, o fundacionismo teria a vantagem de mostrar como o sistema de crenças está relacionado com a realidade não-conceptual. Todavia, argumenta BonJour, a existência de um estado de coisas objetivo apropriado não é suficiente para a justificação. A fonte primária de justificação é a apreensão, por parte do agente doxástico ou sujeito de conhecimento, desses estados de coisas objetivos, uma apreensão que consiste em uma espécie de confronto entre a experiência imediata e a consciência, como se fosse uma visão: "a mente ou a consciência é similar a um olho (imaterial), e o objeto imediatamente experienciado é aquele que está diretamente diante desse olho mental e aberto sem problemas ao seu olhar" (p. 60). A explicação que se oferece para que esse tipo de apreensão tenha o poder justificatório que se diz que ela tem é que ela é imediata, direta, intuitiva ou coisas desse tipo.

BonJour, entretanto, não pretente atacar as versões mais fortes de fundacionismo. O fundacionismo que ele discute é uma versão moderada, que não requer nem que a apreensão do dado seja infalível, nem que o dado seja constituído somente por estados sensoriais ou mentais privados. Assim, pensa BonJour, a crítica vai versar sobre a própria ideia da "dadidade" (giveness), e não apenas sobre coisas que poderiam ser objeto dela. O que BonJour vai mostrar é que qualquer apelo ao dado será insustentável e que qualquer versão de fundacionismo enfrentará um grave dilema, que ele apresenta da seguinte forma:

Se as intuições ou apreensões imediatas ou experiências diretas são concebidas como cognitivas, mais ou menos judicativas (...), então elas serão capazes de dar justificação para outros estados cognitivos e precisarão de justificação elas mesmas; mas se elas forem concebidas como não-cognitivas, não-judicativas, então elas não precisarão de justificação, mas também não poderão transmiti-la (p. 69).

Essa problemática é a forma do celebrado dilema de Sellars: se as experiências são não conceptuais, elas não precisam de justificação, mas também não têm nenhuma para dar; se elas são conceptuais (acarretam crenças), elas podem dar justificação, mas também precisam ser justificadas e, portanto, não podem ser fundacionais. Em outras palavras, o dilema de Sellars se expressa através de um silogismo disjuntivo:

1. ou a apreensão direta envolve apreensão consciente do conteúdo assertivo ou não;

2. se a apreensão direta de fato envolve apreensão consciente do conteúdo assertivo, então essa apreensão transmite justificação somente se ela é epistemicamente apropriada;

3. se a apreensão direta não envolve apreensão consciente de conteúdo assertivo, então ela não pode justificar crenças; portanto 
4. ou a apreensão direta transmite justificação somente se ela é epistemicamente apropriada ou a apreensão não pode justificar crenças; consequentemente,

5. a apreensão direta não pode fornecer justificação fundacional.

O dilema de Sellars implica que (1) experiências sensoriais são desprovidas de conteúdo proposicional e que (2) se um estado mental pode justificar uma crença, então ele tem conteúdo proposicional. Essas duas teses acarretam a conclusão de que experiências sensoriais não podem justificar crenças. Assim, a saída para o fundacionista é rejeitar uma dessas teses.

Matthias Steup (2001) apresenta uma resposta inovadora para esse dilema: ele aceita que, se um estado mental pode justificar uma crença, então ele tem conteúdo proposicional e nega, portanto, que estados sensoriais sejam desprovidos de conteúdo proposicional. Assim, a alternativa parece ser mais promissora se o fundacionista aceitar que somente estados mentais que têm conteúdo proposicional podem justificar crenças. Suponha-se que $S$ tenha a crença de que um certo objeto é azul e a justificação que ele tem para crer nisso é uma experiência visual. Se essa experiência visual não tem conteúdo proposicional, por que essa experiência não justifica, em vez da crença de que esse objeto é azul, a crença de que esse objeto é verde ou a crença de que esse objeto é vermelho? Os externalistas, que exigem uma conexão confiável com a verdade da crença, dirão que aquela experiência visual justifica a crença de que esse objeto é azul porque ela tem uma relação causal confiável com essa crença, mas não com a crença de que esse objeto é verde e nem com a crença de que esse objeto é vermelho. Todavia, o tipo de fundacionismo que se tenta favorecer aqui é internalista e, portanto, a ideia de haver uma relação causal confiável não está disponível. Além disso, uma relação causal não explicaria nem como e nem por que uma crença é justificada. Do ponto de vista do internalismo, portanto, a rejeição do primeiro lado do dilema parece mais promissora: não é verdade que a experiência sensorial seja desprovida de conteúdo proposicional. Daí, a pergunta 'Por que essa experiência sensorial justifica a crença de que este objeto é azul, mas não a crença de que esse objeto é verde e nem a crença de que esse objeto é vermelho?' encontra uma resposta mais direta: essa experiência visual dá essa justificação porque ela tem como seu conteúdo proposicional 'que esse objeto é azul', mas não tem como conteúdo proposicional 'que esse objeto é verde' e nem 'que esse objeto é vermelho'.

Seguindo o argumento de Steup, se for contrastada a posição de que experiências sensoriais são desprovidas de conteúdo proposicional com 
a sua negação, parece claro que a negação tem mais plausibilidade. Pode-se ter várias experiências sensoriais. Por exemplo, ao tomar um café, percebe-se que é preto, que é doce e que é quente. Parece de todo plausível que se pode distinguir aqui três diferentes experiências sensoriais cujo conteúdo proposicional é (1) que o café é preto, (2) que o café é doce e (3) que o café está quente. Steup segue aqui a ideia de Searle de que as experiências sensoriais têm intencionalidade tanto quanto uma crença: as experiências sensoriais são experiências de estados de coisas. Dessa forma podemos dizer que $S$ tem a experiência visual de que esse objeto é azul da mesma forma que se poderia dizer que ele tem a crença de que esse objeto é azul. Assim, o conteúdo da experiência visual, assim como o conteúdo de uma crença, é uma proposição inteira. A experiência visual, portanto, não é apenas de um objeto, mas a experiência de que tal e tal é o caso. Isso não implica que todas as experiências sensoriais tenham conteúdo proposicional. O que Steup pretende defender é a tese mais fraca de que pelo menos algumas dessas experiências têm conteúdo proposicional, e são elas que produzem as crenças básicas que se requerem.

Além disso, continua Steup, há um erro no problema de Sellars, o erro de supor que o fato de que um estado sensorial tenha conteúdo proposicional transformaria esse estado em uma crença ou em um estado similar a uma crença e que, portanto, ele precisaria ser justificado para poder funcionar como justificador. Estados sensoriais são intencionais, mas "nem todos os estados intencionais são capazes de possuir justificação [epistêmica]. (...) entender $\mathrm{p}$ e contemplar $\mathrm{p}$ são estados intencionais, mas dificilmente são tipos de estados que podem ser epistemicamente justificados ou injustificados" (p. 4). Dessa forma, o argumento de que as experiências sensoriais, caso tenham conteúdo proposicional, são estados intencionais e, como tais, se assemelham a estados intencionais como crenças e estados similares, e portanto só podem dar justificação se também são justificados, é um argumento errôneo, porque as experiências sensoriais podem ser estados mentais com conteúdo proposicional que não são passíveis de serem justificados ou injustificados epistemicamente.

O ponto da defesa fundacionista de Steup está no modo de se compreender a experiência sensorial e o próprio caráter da percepção. Essa mesma posição, embora em uma linha de argumentação diferente, encontra-se em Robert Audi. Audi (2003) mostra que a objeção postulada no problema de Sellars presume que somente aquilo que tem justificação poderá também dá-la, mas não há argumento que mostre que isso seja assim. O problema de Sellars contém algo contraintuitivo, porque conferir justificação não é o mesmo que transmitir justificação. Quando 
$S$ justifica sua crença de que tem um gato branco no telhado ele diz 'eu vejo um gato branco no telhado', e só então o conteúdo da crença é conceptualizado. Mas, a conceptualização da indicação da base de $S$ para a crença não implica que a própria base seja conceptualizada. O que $S$ faz ao dizer 'eu vejo um gato branco no telhado' é apresentar uma razão em favor de sua crença. Essa razão indica a da crença, a visão, mas não é ela mesma a da crença, a experiência visual. A experiência visual, entretanto, tem qualidades que podem estar em relação lógica com o conteúdo da proposição em que $S$ crê: "a propriedade fenomênica de eu estar tendo a impressão visual de cinza é, de certa maneira, apropriada à propriedade de ser cinza: a instanciação interna da primeira é pelo menos discutivelmente mais bem explicada pela causação através da instanciação externa da segunda" (Audi, 2001, p. 18). Mas, a relação de justificação é epistêmica, e não uma relação lógica. Daí que, para algo conferir justificação, não precisa que seja de modo inferencial.

Pryor (2000) também defende, em uma direção diferente, que a objeção de Sellars e BonJour não se sustenta. A experiência pode não ter um caráter totalmente subjetivo ou sensorial. Pryor assume, seguindo recentes teorias da mente, que as experiências são estados mentais que têm conteúdo proposicional: "suas experiências representam, para você, o mundo de um certo modo, e o modo como elas representam que o mundo é vem a ser o conteúdo proposicional dela" (2000, p. 519). $\mathrm{O}$ fato de se ter uma certa experiência sensorial apresenta à mente o conteúdo proposicional dessa experiência, dispensando qualquer crença sobre os estados de coisa com os quais a experiência está conectada. O fundacionismo defendido por Pryor é dogmático e consiste em que a experiência que representa $p$ como sendo o caso é suficiente para dar justificação para a crença de que $p$. Contra o fundacionismo clássico, o fundacionismo dogmático de Pryor não requer que $S$ esteja consciente da experiência que ele está tendo para que ele tenha justificação para a crença que ele forma. A justificação para $S$ crer que $p$ é obtida do fato de que $S$ tem aquela experiência, mas essa experiência não pode ser considerada como uma evidência para $S$ crer que $p$ se isso sugere que a crença perceptual depende de justificação de premissas sobre essas experiências: não é preciso que $S$ esteja introspectivamente consciente da experiência que ele está tendo e que sua crença esteja baseada nessa consciência: "o dogmatista pensa que o mero fato de ter uma experiência como se fosse $p$ é suficiente para que a justificação perceptual para crer que $p$ esteja em ordem. Você não tem que estar, além disso, consciente de suas experiências e apelar a fatos sobre elas como 'evidência' para suas crenças perceptuais" (Pryor, 2000, p. 519). 


\section{A plausibilidade do fundacionismo moderado}

Essas explicações de Steup, Audi e Pryor constituem defesas de versões moderadas de fundacionismo e, quer parecer, compromete-os também com uma defesa de realismo direto, ao contrário das versões fundacionistas tradicionais. O entendimento de Audi sobre o caráter da percepção mostra bem a plausibilidade de um fundacionismo moderado.

Ora, a percepção é uma fonte de justificação (e de conhecimento) em virtude de produzir crenças justificadas. Quando $S$ olha pela janela e percebe que há um gato branco no telhado, ele forma a crença de que há um gato branco no telhado e a crença de que ele está vendo um gato branco no telhado. Há, pelo menos, quatro elementos envolvidos na percepção: aquele que percebe, o objeto percebido, a experiência sensorial e a relação entre o objeto percebido e aquele que o percebe, uma relação causal pela qual o objeto produz uma experiência sensorial naquele que o percebe.

Parece que há três tipos de percepção: a percepção simples, como quando se diz que $S$ vê o gato branco no telhado; a percepção objetual, como quando se diz que $S$ vê que o gato é branco e está no telhado; e a percepção proposicional, como quando se diz que $S$ vê que há um gato branco no telhado. A percepção simples é constituinte da percepção objetual e da percepção proposicional; mas, é importante distingui-las devido à relação que elas têm com a justificação. Perceber que o gato é branco e está no telhado e perceber que há um gato branco no telhado implica crer que o gato é branco e está no telhado e crer que há um gato branco no telhado. As crenças dependem dos recursos conceptuais que se tem, mas a percepção simples não. Se $S$ não tivesse o conceito de gato, o conceito de branco e o conceito de telhado, ele não seria capaz de formar as crenças de que o gato é branco e está no telhado e de que há um gato branco no telhado, ainda que ele tivesse a experiência visual para fundamentar essas crenças. Através da experiência visual $S$ poderia ver que há um animal felpudo sobre uma certa superfície, mas ele não poderia formar a crença de que ele vê um gato branco no telhado e nem a crença de que há um gato branco no telhado. Uma vez que as crenças que interessam para a justificação epistêmica são as crenças proposicionais, é importante notar a dependência delas em relação aos recursos conceptuais.

Algumas das crenças que se formam a partir da percepção são crenças proposicionais e outras são crenças objetuais. Esses dois tipos de crenças correspondem a duas maneiras diferentes de se estar relacionado com o objeto que se percebe e a duas maneiras distintas de se captar a verdade daquilo em que se crê com base na percepção. 
O primeiro tipo de crença é um caso de se crer em uma proposição. A verdade ou a falsidade da crença depende da verdade ou da falsidade da proposição em que se crê. O segundo tipo de crença diz respeito ao objeto com o qual a crença está realmente conectada. No exemplo dado, é um objeto do qual $S$ crê que é branco e que está no telhado. Assim, realmente há tal objeto (o gato) e $S$ tem uma certa relação com ele, mas essa relação não implica que haja qualquer proposição a respeito do gato na qual $S$ deveria crer. $S$ pode crer que o gato é branco e está no telhado mesmo que ele esteja enganado e tome algo artificial como sendo o gato. Isso significa que $S$ pode pensar sobre o gato apenas em termos do que ele acredita que o gato seja e não em termos do que o gato obviamente é. Através da percepção, formam-se crenças objetuais sobre os objetos a partir de perspectivas diferentes e forma-se um conceito do que o objeto é. Parece, então, que o conhecimento das propriedades perceptíveis é mais básica do que o conhecimento dos objetos que as possuem.

A verdade das crenças proposicionais depende da verdade da proposição em que se crê; a verdade das crenças objetuais depende de se aquilo em que se crê sobre o objeto é verdadeiro ou falso. Dessa forma, se $S$ crê que há um gato branco no telhado, essa crença será verdadeira se há um gato branco no telhado; se $S$ crê que o gato é branco e está no telhado, essa crença será verdadeira se aquilo que ele toma como sendo um gato é branco e está no telhado (isto é, mesmo que ele não saiba que aquilo que ele vê é um gato).

As crenças proposicionais e as crenças objetuais têm contrapartes: percepções proposicionais e percepções objetuais. As crenças perceptuais estão ligadas às percepções objetuais e proposicionais, e é nessas percepções objetuais e proposicionais que as crenças perceptuais fundamentam a sua autoridade. A crença de $S$ de que há um gato branco no telhado é vinculada à percepção de $S$ de que há um gato branco no telhado. Assim, não há percepção desse tipo que não resulte em uma crença. São percepções cognitivas, já que a crença é uma atitude cognitiva.

As crenças proposicionais e objetuais são fundadas na percepção simples, uma vez que, se $S$ não visse o gato, ele não veria que o gato está no telhado e nem que ele é branco. O tipo de justificação que as crenças perceptuais oferecem pode diferir de acordo com o fundamento que elas têm: se na percepção proposicional ou na percepção objetual. A percepção proposicional dá justificação para o que é que se percebe e suas propriedades, ao passo que a percepção objetual dá justificação apenas para as propriedades percebidas, já que se pode não saber de que objeto se trata. 
As crenças perceptuais são fundadas na percepção de uma maneira que conecta o sujeito com o mundo exterior e garante a verdade das crenças. A crença visual de $S$ de que há um gato branco no telhado está fundada na visão que $S$ tem do gato de tal maneira que ele verdadeiramente vê que o gato está no telhado. Sem dúvida, a crença fundada na visão pode estar errada (pode ser uma ilusão de ótica, por exemplo), mas nesse caso a crença não está conectada com a percepção proposicional, porque $S$ não vê o que parece que ele está vendo. O clássico exemplo da vareta que se curva no copo d'água mostra isso: $S$ genuinamente vê a vareta curvada, mas ele não vê a curvatura. Se ele visse a curvatura, isso acarretaria que a vareta está curvada, mas como a vareta não está curvada, $S$ não pode ver que ela está curvada. A percepção proposicional e a percepção objetual são experiências verídicas: elas implicam a verdade.

A percepção proposicional e a percepção objetual produzem crenças, mas a percepção simples não. Frequentemente acontece que se ouvem muitas coisas e se vêem muitas coisas durante uma conversa, mas não é preciso que se formem crenças a respeito do que se vê e do que se ouve, já que isso não tem significância naquele momento, embora, se fosse o caso, a pessoa estaria em posição de formar crenças a respeito disso. Isso vale para todos os sentidos. Parece claro que ver alguma coisa coloca a pessoa em posição de formar pelo menos uma crença a respeito daquilo que ela vê. Se $S$ vê uma lapiseira sobre a mesa parece que ele poderia formar a crença de que se trata de um objeto inanimado. Isso permite concluir que a evidência dos sentidos normalmente dá justificação para as crenças nos conteúdos apropriados àquela evidência: "ver um objeto sempre dá justificação prima facie para crer uma coisa ou outra sobre ele, em que justificação prima facie é, grosso modo, justificação que prevalece a não ser que seja anulada por fatores tais como uma justificação forte para crer em algo contrário, por exemplo" (Audi, 2003, p. 27). Não se pode concluir, todavia, que todas as crenças perceptuais sejam justificadas: elas podem ter sido formadas em condições inadequadas, sob alucinação, ou tendenciosamente, ou qualquer coisa dessa ordem. Mas, parece mesmo que a percepção dá pelo menos uma justificação situacional: justificação para formar uma crença nas proposições para as quais se tem justificação.

Aqui, pode-se formular um princípio plausível: "normalmente, uma crença visual que é constituída por ver que algo é assim ou por ver algo ser assim é justificada (e ela é sempre justificada prima facie)" (Audi, 2003, p. 27). O princípio, entretanto, não descarta a possibilidade de se encontrar anuladores aqui: se $S$ se der conta de que à tarde ele confunde coelhos com gatos, ele não está justificado em crer que hoje à tarde ele viu um gato branco no telhado, mesmo que isso seja verdadeiro. Por outro 
lado, se $S$ não tem a menor ideia dessa confusão que ele faz, ou de que ele está alucinado, etc., então ele está justificado em crer que há um gato branco no telhado. Assim, pode-se dizer que uma crença é justificada sempre que se crê em algo do tipo que a experiência perceptual parece mostrar, desde que tudo o que concerne à experiência seja aparentemente normal.

Isso mostra que é possível debelar o problema de Sellars e promover uma defesa de uma versão de fundacionismo moderado. Há, certamente, muito mais para se dizer sobre o problema de Sellars. Especialmente, valeria o estudo das análises de Alston (2002) e de Kvanvig (2005), mas isso desviaria o foco que se pretendia aqui.

\section{Referências}

ARISTOTELES. "Analytica Posteriora". In: MCKEON, Richard (ed.). The Basic Works of Aristotle. New York: Modern Library, 2001, p. 110-186.

ALSTON, William. "Sellars and the 'Myth of the Given'". In: Philosophy and Phenomenological Research, 65 (2002): 1, p. 69-86.

AUDI, Robert. The Architecture of Reason. Oxford: Oxford University Press, 2001.

Epistemology. A Contemporary Introduction to the Theory of Knowledge. London: Routledge, 2003.

BONJOUR, Laurence. The Strucuture of Empirical Knowledge. Cambridge (MA): Harvard University Press, 1985.

KVANVIG, Jonathan. “On Denying a Pressuposition of Sellars' Problem: A Defense of Propositionalism". In: Veritas, 50 (2005): 4, p. 173-190.

POLLOCK, John; CRUZ, Joseph. Contemporary Theories of Knowledge. 2. ed. Lanham (MD): Rowman \& Littlefield, 1999.

POSTON, Ted. Sellars and Socrates: an Investigation of the Sellars Problem for a Socratic Epistemology. Tese de Doutorado em Filosofia. Columbia: University of Missouri, 2006.

PRYOR, James. “The Skeptic and the Dogmatist”. In: Noûs, 34 (2000): 4, p. 517-549.

SEARLE, John. Intencionalidade. (Tradução de Julio Fischer e Tomás Rosa Bueno). São Paulo: Martins Fontes, 1995.

SELLARS, Wilfrid. Empirismo e Filosofia da Mente. (Tradução de Sofia Inês Albornoz Stein). Petrópolis: Vozes, 2008.

."Epistemic Principles". In: SOSA, Ernest; KIM, Jaegwon (ed.). Epistemology. An Anthology. Oxford: Blackwell, 2000A, p. 125-133.

"Does Empirical Knowledge Have a Foundation?". In: BERNECKER, Sven; DRETSKE, Fred. Knowledge. Readings in Contemporary Epistemology. New York: Oxford University Press, 2000B, p. 260-265.

STEUP, Matthias. Foundationalism, Sense-Experiential Content, and Sellars's Dilemma, 2001. Disponível em: http://web.stcloudstate.edu/msteup/SellDilem.htlm 